\title{
Right Ventricular Cardiomyopathy Showing Right Bundle Branch Block and Right Precordial ST Segment Elevation
}

\author{
Tomoko Izumi, Kohsuke AJiki, Akira Nozaki, Saeko TAKahashi, Fumiko Tabei, \\ Hiroshi HaYAKAWA and Tsuneaki Sugimoto
}

\begin{abstract}
A 73-year-old man who had a family history of sudden death, experienced syncope. His electrocardiogram (ECG) presented right bundle branch block and right precordial ST segment elevation which are findings identical with those in Brugada syndrome. The cardiac MRI showed right ventricular mild dilatation, and endomyocardial biopsy revealed fatty replacement of myocardial fibers. Though no ventricular tachyarrhythmias were induced during an electrophysiologic test, the effects on ECG of antiarrhythmic agents and autonomic modulations were similar to those in Brugada syndrome. This case may suggest the relationship between Brugada syndrome and right ventricular cardiomyopathy.

(Internal Medicine 39: 28-33, 2000)
\end{abstract}

Key words: Brugada syndrome, antiarrhythmic agents, autonomic modulation

\section{Introduction}

In 1992 Brugada and Brugada reported cases with right bundle branch block (RBBB), persistent right precordial ST segment elevation without QT interval prolongation, and aborted sudden death due to ventricular fibrillation (1). Though they found no evidence of structural heart disease, some investigators suggested that right ventricular cardiomyopathy (RVC) might underlie this syndrome $(2,3)$, and the pathogenesis of this clinical entity is controversial. Another feature worthy of note is that the unusual ECG pattern in this syndrome may vary over time or by some pharmacological intervention (4 6). Here, we report a case of RVC with an ECG identical to that in Brugada syndrome. In addition, we investigated the effects of autonomic modulations and the effects of antiarrhythmic agents on ST segment elevation in attempt to elucidate the mechanism of the bizarre ECG patterns.

\section{Case Report}

A 73-old-year man was referred to our hospital because of syncopal episodes and precordial oppression. His younger brother had died suddenly at the age of 58 years. All the examinations in this article were performed according to the ethical guidelines of our institution and after obtaining informed consent.

The physical examination showed no abnormalities except systolic ejection murmur at the left sternal border in the fourth intercostal space (Levine II/VI). Blood chemistry revealed mild hypokalemia of $3.4 \mathrm{mEq} / l$ and slightly increased CRP of 0.76 $\mathrm{mg} / \mathrm{dl}$. Both abnormalities were normalized at the follow-up examination performed several days later. The ECG showed complete RBBB and ST segment elevation in right precordial leads (Fig. 1). Two-dimensional echocardiogram, treadmill exercise test, Holter ECG, and brain MRI all revealed normal findings. Late potential during sinus rhythm could not be detected. Head-up tilt testing could induce neither syncope nor a significant decrease in blood pressure and heart rate with or without administration of isoproterenol. The coronary angiography and both ventriculograms were normal, and intracoronary administration of acetylcholine (up to $50 \mu \mathrm{g}$ into the right and up to $80 \mu \mathrm{g}$ into the left coronary artery) did not induce coronary vasospasm. Cardiac MRI showed mild dilatation of the right ventricle (Fig. 2), and endomyocardial biopsy from the right ventricular septum revealed fatty replacement of myocardial fibers (Fig. 3). In an electrophysiologic test, the HV interval was prolonged to $80 \mathrm{msec}$. Up to 2 extrastimuli and overdrive pacing at a pacing rate up to $200 \mathrm{ppm}$ applied to the right ventricular apex and to right ventricular outflow tract induced no ventricular tachyarrhythmias before and after administration of isoproterenol. No abnormal electrograms, including fractionation, double potentials and delayed potential, were recorded during right ventricular endocardial mapping.

We examined the effects on ECG findings of autonomic re-

From the Division of Cardiology, Kanto Central Hospital, Tokyo

Received for publication March 30, 1999; Accepted for publication July 24, 1999

Reprint requests should be addressed to Dr. Kohsuke Ajiki, the Department of Cardiovascular Medicine, Graduate School of Medicine, University of Tokyo, 7 3-1 Hongo, Bunkyo-ku, Tokyo 113-8655 


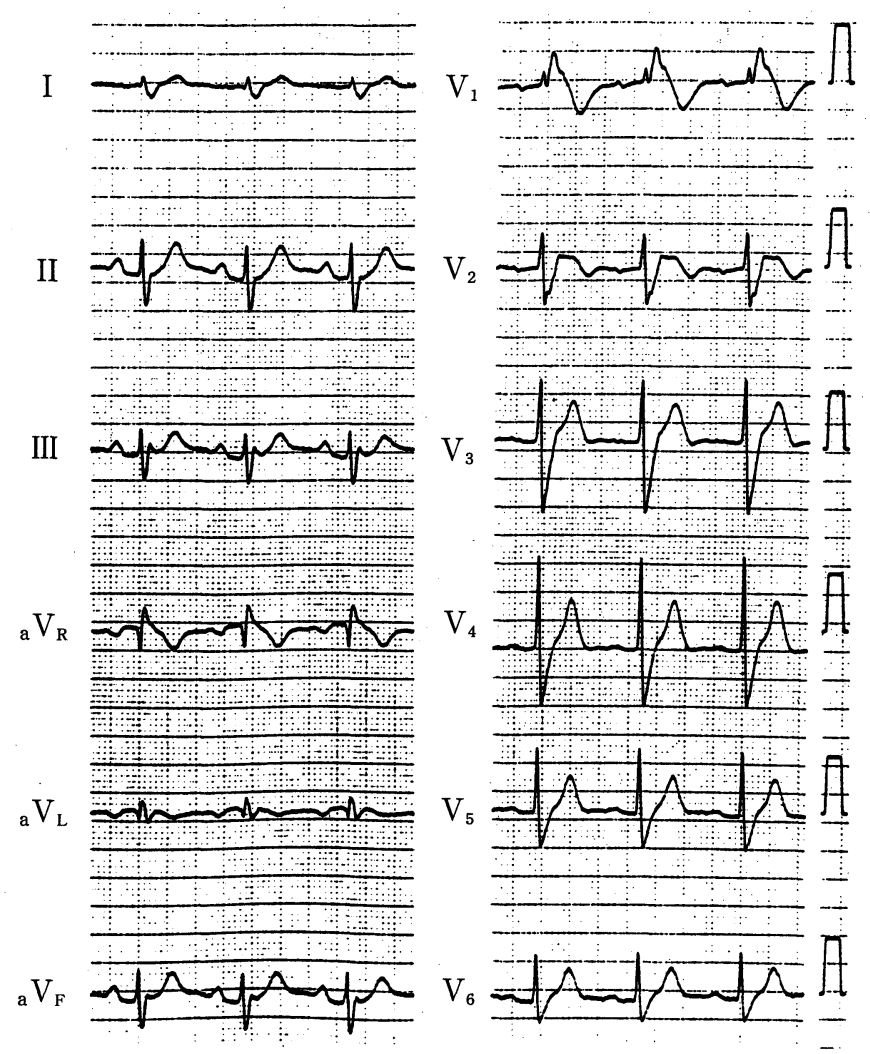

Figure 1. Twelve-lead ECG showing right bundle branch block and $S T$ segment elevation in leads $V_{1}$ and $V_{2}$.

ceptor stimulation or blockade and the effects of antiarrhythmic agents in a drug-free state. For the quantitative evaluation of the ECG changes, the upward deviations of the J-point in lead $V_{2}$ from the ECG baseline were measured. Muscarinic receptor stimulation by edorophonium $(10 \mathrm{mg}$ iv) slightly increased the elevation of the J-point in $\mathrm{V}_{2}$ from $0.05 \mathrm{mV}$ to 0.10 $\mathrm{mV}$, and muscarinic blockade by atropine sulfate $(0.04 \mathrm{mg} / \mathrm{kg}$ iv) did not influence the ECG pattern (Fig. 4). Betaadrenoreceptor stimulation by continuous infusion of isoproterenol $(0.01 \mu \mathrm{g} / \mathrm{kg} / \mathrm{min}$ div) lowered the point of take-off of ST segment by $0.20 \mathrm{mV}$ to site at ECG baseline, but it was again elevated by $0.10 \mathrm{mV}$ after $\beta$ blockade by additional administration of propranolol $(0.2 \mathrm{mg} / \mathrm{kg}$ iv) (Fig. 5). The effects of $\alpha$-adrenoreceptor manipulation were imperceptible; $\alpha$ stimulation by continuous infusion of phenyrephrine $(0.4 \mu \mathrm{g} / \mathrm{kg} / \mathrm{min}$ div) slightly augmented the elevation of the J-point from 0.10 $\mathrm{mV}$ to $0.15 \mathrm{mV}$, while consequent $\alpha$ blockade by phentolamin $(0.2 \mathrm{mg} / \mathrm{kg}$ iv) eliminated the change (Fig. 6). Sodium channel blockers augmented ST segment elevation without exception, but prominent ST segment elevation was observed after administration of class IA (Fig. 7A) and IC (Fig. 7C) agents while the effect of class IB (Fig. 7B) was very mild. The administration of disopyramide (50 $\mathrm{mg}$ iv), flecainide $(100 \mathrm{mg} \mathrm{po}$ ) and pilsicainide ( $150 \mathrm{mg} \mathrm{po}$ ) exacerbated the J-point elevation by $0.30 \mathrm{mV}, 0.30 \mathrm{mV}$ and $0.40 \mathrm{mV}$ compared to the baseline state,



Figure 2. Cardiac MRI showing mild dilatation of the right ventricle.

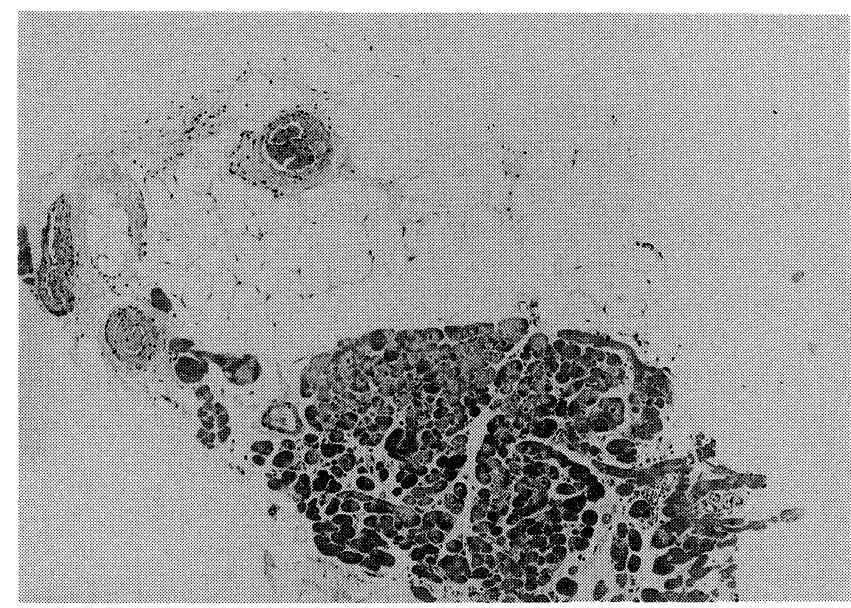

Figure 3. Endomyocardial biopsy from right ventricular septum revealed fatty replacement of myocardial fibers (HE stain, $\times 25)$.

respectively (Fig. 7A \& C). On the other hand, the elevation of the J-point by mexiletine ( $125 \mathrm{mg}$ iv) was no more than 0.10 $\mathrm{mV}$ (Fig. 7B). These effects were thought to occur in a dosedependent manner as shown in the example of procainamide. The level of the J-point at the baseline state was $0.20 \mathrm{mV}$, but after the intravenous administration of procainamide of 200 $\mathrm{mg}$ and of $500 \mathrm{mg}$, the levels of the J-point were $0.30 \mathrm{mV}$ and $0.50 \mathrm{mV}$, respectively (Fig. 7A). Calcium channel blockade by verapamil ( $5 \mathrm{mg}$ iv) slightly eliminated the elevation of J-point by $0.05 \mathrm{mV}$. The potassium channel opener, nicorandil, did not affect the ECG not only when administrated solely but also when given after the administration of procainamide (Fig. 8).

As we considered that the present patient is at high risk of sudden death, we recommended the implantation of an implantable cardioverter-defibrillator (ICD), but he did not agree. He was treated with oral disopyramide ( $300 \mathrm{mg} /$ day) and has been 


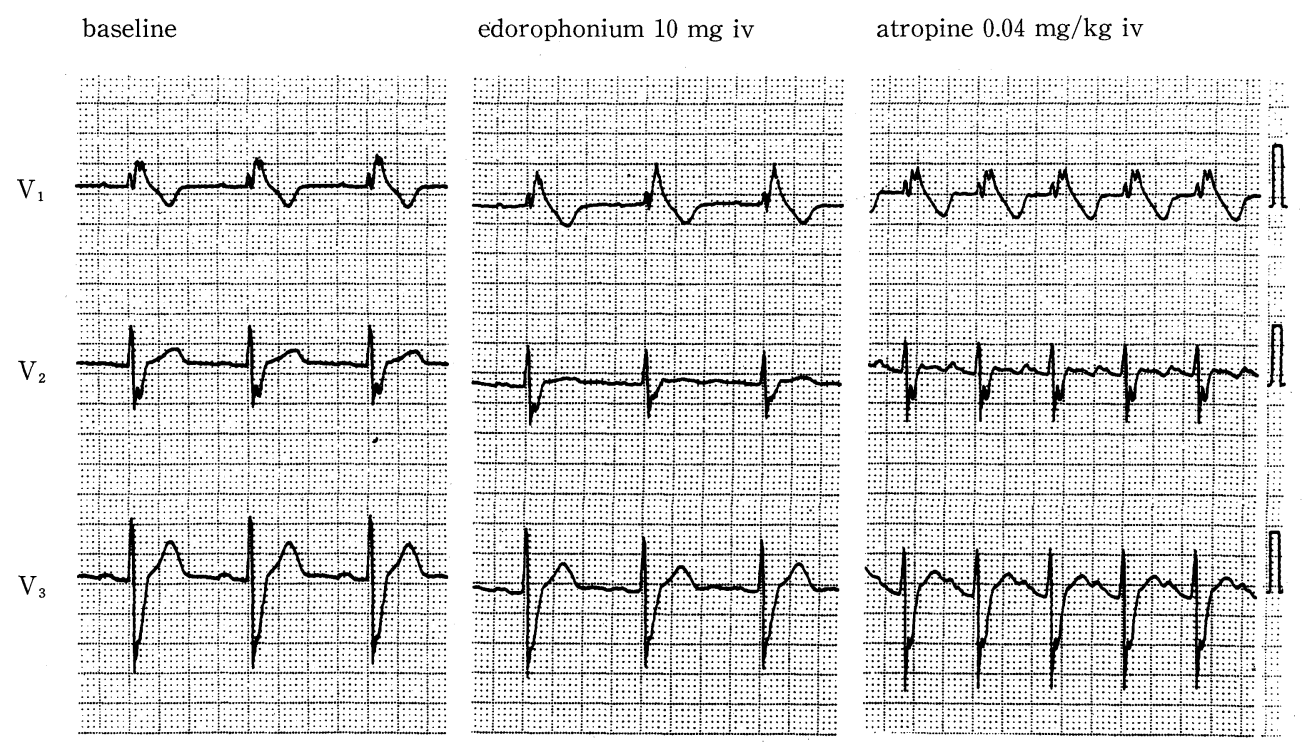

Figure 4. The effect on ECG of muscarinic receptor stimulation and blockade. Compared to the baseline state, mild elevation of the $J$-point was observed in lead $V_{2}$ after the administration of edorophonium. Consequent muscarinic blockade by additional administration of atropine sulfate did not influence the ST segment.

baseline isoproterenol $0.01 \mu \mathrm{g} / \mathrm{kg} / \mathrm{min} \operatorname{div}$ propranolol $0.2 \mathrm{mg} / \mathrm{kg}$ iv
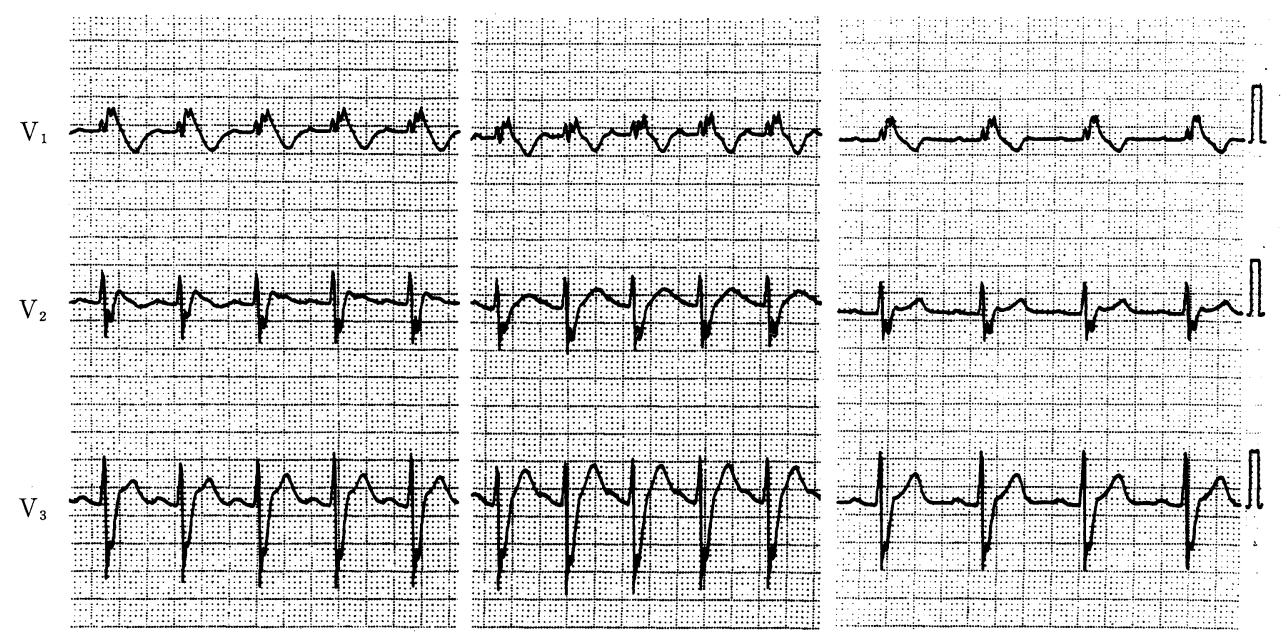

Figure 5. The effect on ECG of $\beta$-adrenoreceptor stimulation and blockade. Beta stimulation by continuous infusion of isoproterenol reduced ST segment elevation and lowered the point of take-off of ST segment. Beta blockade by additional administration of propranolol restored the ST segment elevation.

asymptomatic for 10 months.

\section{Discussion}

Since the report by Brugada and Brugada (1), a clinical syndrome characterized by the ECG pattern of RBBB with right precordial ST segment elevation and sudden cardiac death
(Brugada syndrome) has been drawing electrophysiologists' attention. However, the pathogenesis of lethal ventricular arrhythmias and the mechanisms of the queer ECG pattern in this syndrome remain obscure. In the first report (1) as well as in the consequent studies $(6,7)$, Brugada et al did not demonstrate the presence of structural heart disease, while some investigators have suggested that right ventricular myocardial 


\section{RVC with Brugada Type ECG}

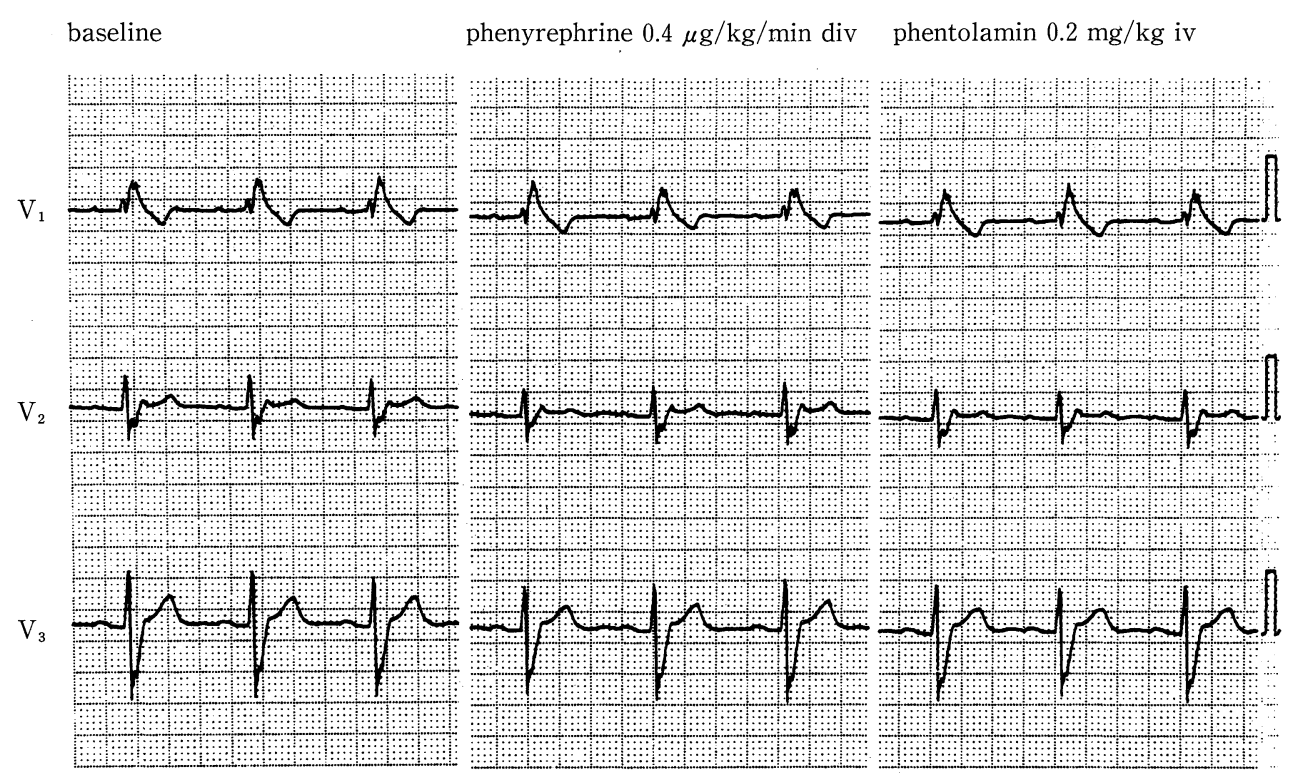

Figure 6. The effects on ECG of $\alpha$-adrenoreceptor stimulation and blockade. Alfa stimulation by continuous infusion of phenyrephrine slightly augmented ST segment elevation and consequent $\alpha$ blockade by phentolamin eliminated the change, but these changes are not significant.

diseases might underlie the syndrome $(2,3)$.

In the present case, the ECG was identical with that in Brugada syndrome, and the effects of autonomic modulations and of antiarrhythmic agents also closely resembled those reported by Miyazaki et al (5): Other features, including familial history of sudden death, prolonged HV interval and negative late potential are also suggestive of Brugada syndrome. Based on these reasons we think his disease is this syndrome or, at least, something highly close to it, though the electrophysiologic test failed to demonstrate ventricular tachyarrhythmias. We could not find any structural heart disease by echocardiography, coronary angiography or ventriculography, but the results of cardiac MRI and endomyocardial biopsy suggested RVC. There have been several reports suggesting the close connection between RVC and Brugada syndrome. It has been known that the ECG pattern of RBBB with right precordial ST segment elevation as seen in patients with Brugada syndrome is sometimes observed in patients with RVC (8). Corrado et al described the link between right bundle branch block, ST segment elevation and sudden death with familial RVC (2), and Tada et al reported the high incidence of morphological and histologic abnormalities in right ventricle in patients with Brugada syndrome (3). These reports as well as the present case are apparently inconsistent with the original observations that Brugada et al could not detect the presence of a myocardial histological abnormality in 16 patients following myocardial biopsy (6), but it seems reasonable to suppose that the degree of myocardial degeneration in RVC is varied. For example, Nava et al suggested the concept of a "concealed" form of arrhythmogenic RVC in patients with apparently idiopathic ventricular arrhythmias (9). Thus, we speculate that RVC with mild and focal myocardial degeneration, which can be easily overlooked by routine examinations, may underlie one of the etiologies of Brugada syndrome.

The ECG in Brugada syndrome is characterized by RBBB and right precordial ST segment elevation (1). These changes could not be explained by electrolyte abnormality, myocardial ischemia or atrial repolarization, and have been ascribed to early repolarization, injury current due to focal depolarization or right ventricular conduction delay (10). Yan and Antzelevitch observed that the $\mathbf{J}$ wave was closely related to an action potential notch especially in the epicardium and suggested the participation of transient outward current Ito or $\mathrm{I}_{\mathrm{Ca}}(11)$. In contrast, Corrado et al presumed that right ventricular conduction delay might be the main factor for the ECG pattern (2). It is difficult to determine which mechanism is responsible for the strange ECG pattern in Brugada syndrome from our study. However, it is interesting to note that pilsicainide, a selective sodium channel blocker (12), provoked prominent ST elevation, just as flecainide and class IA antiarrhythmic agents together possess potassium channel blocking effects. It cannot be denied that sodium channel blocking can alter potassium conductance and consequently affect the repolarization process through the decrease of the net inward current during upstroke of action potential. However, it would be unlikely that the augmentation of ST elevation by pilsicainide is mainly a result of the alteration in repolarization. Also depolarization block seems to be improbable as a cause for ST elevation, because Miyazaki et al reported the absence of late potential or intracardiac abnormal electrograms in spite of prominent ST segment elevation as in our case (5). Functional abnormality of the cardiac sodium channel, as in hereditary long QT syndrome, may account for 
A

baseline

disopyramide $50 \mathrm{mg}$ iv baseline

procainamide $200 \mathrm{mg}$ iv procainamide $500 \mathrm{mg}$ iv

$\mathrm{V}_{1}$

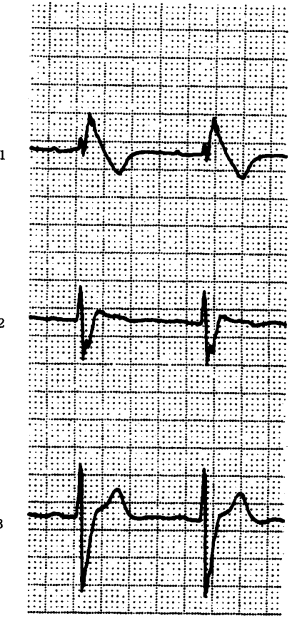

B

baseline
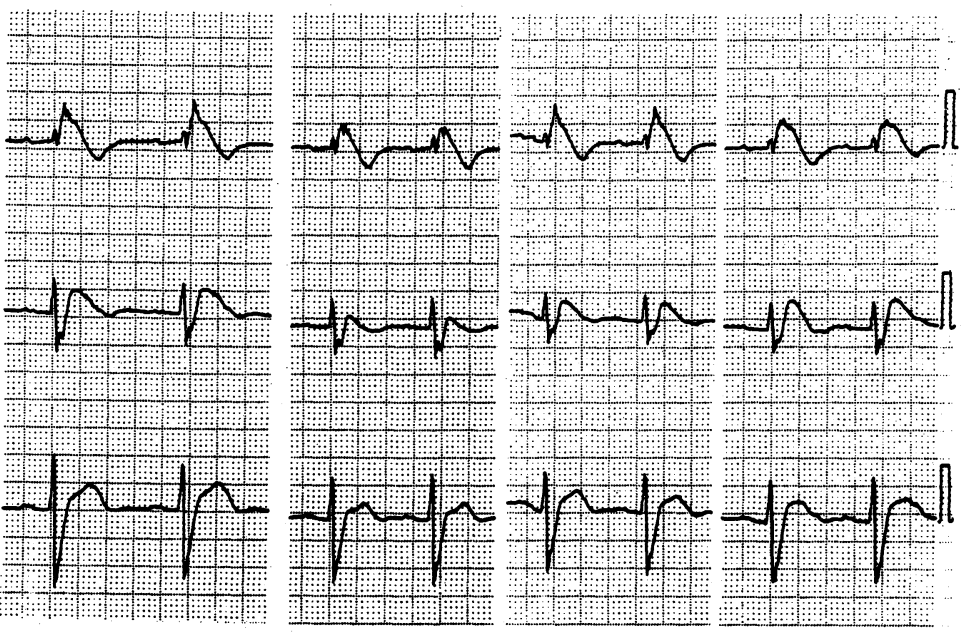

mexiletine $125 \mathrm{mg}$ iv

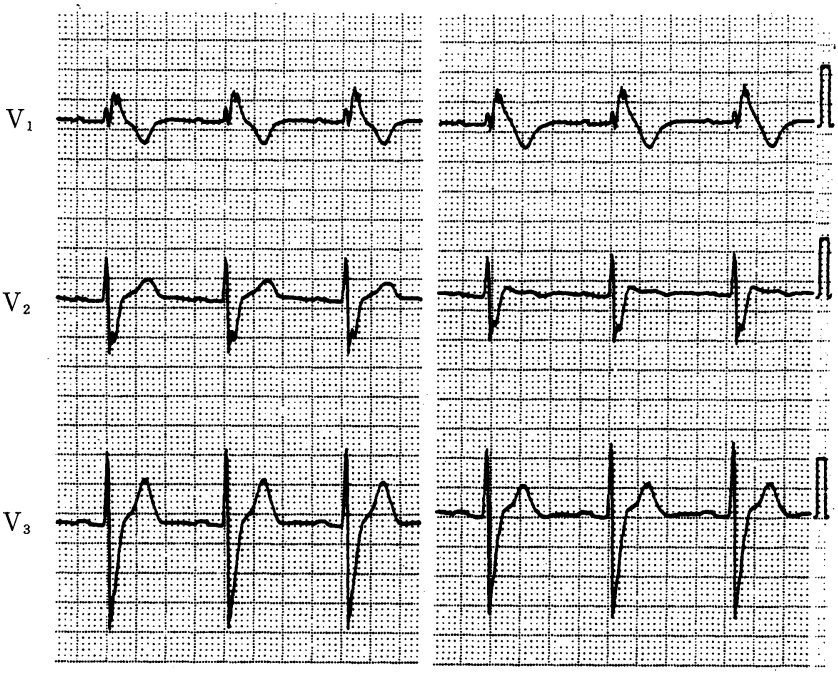

$\mathrm{C}$

baseline flecainide $100 \mathrm{mg}$ po baseline

pilsicainide $150 \mathrm{mg}$ po



Figure 7. The effects on ECG of sodium channel blockers. All sodium channel blockers augmented ST segment elevation. A: Class IA agents, disopyramide and procainamide, evoked prominent ST segment elevation. Dose dependency was observed after administration of procainamide. B: Class IB agent, mexiletine, augmented ST segment elevation, but the effect was much milder than that of class IA or IC agents. C: Class IC agents, pilsicainide and flecainide, evoked prominent ST segment elevation as class IA agents. 


\section{RVC with Brugada Type ECG}

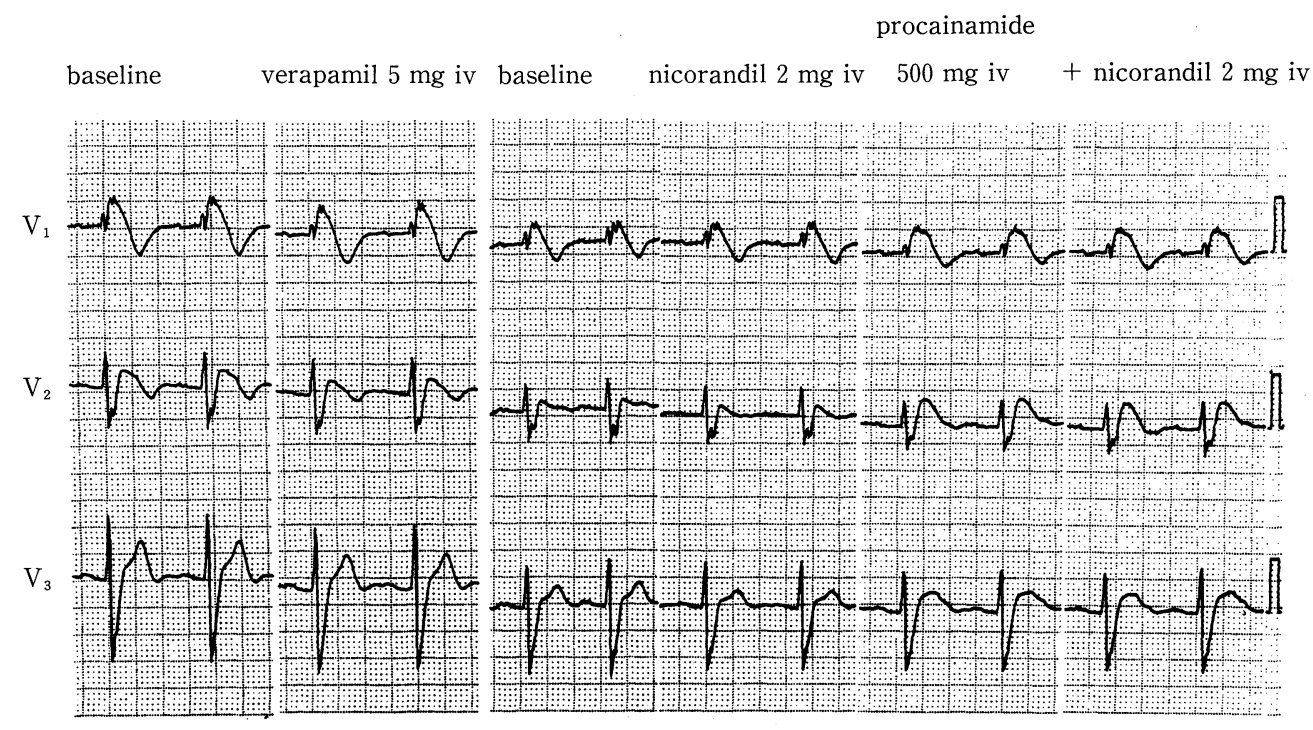

Figure 8. The effect on ECG of a calcium channel blocker and a potassium channel opener. Calcium channel blockade by verapamil slightly eliminated ST segment elevation. The potassium channel opener, nicorandil, did not affect the ST segment not only when administrated solely but also when given after the administration of procainamide.

the ECG response to antiarrhythmic agents (13), though this possibility needs further evaluation.

Brugada et al reported that the mortality came up to about $30 \%$ in pharmacologically treated or non-treated patients while it was $0 \%$ in those treated with an ICD (7). Therefore, we recommended the implantation of ICD, but our patient did not agree. As of now, though no particular antiarrhythmic agents have seemed useful in preventing lethal ventricular arrhythmias, Chinushi et al described a patient in whom disopyramide effectively suppressed ventricular arrhythmias though it concurrently augmented ST segment elevation (14). Referring to their report, we treated our patient with disopyramide as an alternative therapy, but further investigation will be necessary.

Acknowledgements: We are grateful to Dr. Hideaki Yasui for his professional aid in pathological problems.

\section{References}

1) Brugada P, Brugada J. Right bundle branch block, persistent ST segment elevation and sudden cardiac death: a distinct clinical and electrocardiographic syndrome. A multicenter report. J Am Coll Cardiol 20: 13911396, 1992.

2) Corrado D, Nava A, Buja G, et al. Familial cardiomyopathy underlies syndrome of right bundle branch block, ST segment elevation and sudden death. J Am Coll Cardiol 27: 443-448, 1996.

3) Tada $\mathrm{H}$, Aihara N, Ohe T, et al. Arrhythmogenic right ventricular cardiomyopathy underlies syndrome of right bundle branch block, ST-segment elevation, and sudden death. Am J Cardiol 81: 519-522, 1998.

4) Atarashi H, Ogawa S, Harumi K, et al and Idiopathic Ventricular Fibrillation Investigators. Characteristics of patients with right bundle branch block and ST-segment elevation in right precordial leads. Am J Cardiol 78: 581-583, 1996.

5) Miyazaki T, Mitamura H, Miyoshi S, Soejima K, Aizawa Y, Ogawa S. Autonomic and antiarrhythmic drug modulation of ST segment elevation in patients with Brugada syndrome. J Am Coll Cardiol 27: 1061-1070, 1996.

6) Brugada J, Brugada P. Further characterization of the syndrome of right bundle branch block, ST segment elevation, and sudden cardiac death. J Cardiovasc Electrophysiol 8: 325-331, 1997.

7) Brugada J, Brugada R, Brugada P. Right bundle-branch block and STsegment elevation in leads V1 through V3: A marker for sudden death in patients without demonstrable structural heart disease. Circulation 97: 457-460, 1998.

8) Fontaine G, Fontaliran F, Lascault G, Aouate P, Tonet J, Frank R. Arrhythmogenic right ventricular dysplasia. in: Cardiac Electrophysiology: From Cell to Bedside. 2nd ed. Zipes DP, Jalife J, Eds. W. B. Saunders Company, Pennsylvania, 1995: 754-768.

9) Nava A, Thiene G, Canciani B, et al. Clinical profile of concealed form of arrhythmogenic right ventricular cardiomyopathy presenting with apparently idiopathic ventricular arrhythmias. Int J Cardiol 35: 195-206, 1992.

10) Scheinman MM. Is the Brugada syndrome a distinct clinical entity? J Cardiovasc Electrophysiol 8: 332-336, 1997.

11) Yan GX, Antzelevitch C. Cellular basis for the electrocardiographic $J$ wave. Circulation 93: 372-379, 1996.

12) Hattori $Y$, Inomata $N$, Aisaka $K$, Ishihara $T$. Electrophysiological actions of $\mathrm{N}$-(2, 6-dimethylphenyl)-8-pyrrolizineacetamide hydrochloride hemihydrate (SUN1165), a new antiarrhythmic agent. J Cardiovasc Pharmacol 8: 998-1002, 1986.

13) Chen Q, Kirsch GE, Zhang D, et al. Genetic basis and molecular mechanism for idiopathic ventricular fibrillation. Nature 392: 293-296, 1998.

14) Chinushi M, Aizawa Y, Ogawa Y, Shiba M, Takahashi K. Discrepant drug action of disopyramide on ECG abnormalities and induction of ventricular arrhythmias in a patient with Brugada syndrome. J Electrocardiol 30: 133-136, 1997. 